\title{
PRACTICAL STUDY OF PONGAMIA BIODIESEL AND DIESEL IN LHR CI ENGINE
}

\author{
Manjula $^{1}$, Srinivas. ${ }^{2}$, Praveen Anthony ${ }^{3}$ Bharadwaj $^{4}$ \\ ${ }^{1,2,3,4}$ Assistant Professor T John Institute of Technology, Bangalore. \\ 'manjubennur99@gmail.com
}

\begin{abstract}
Biodiesel from vegetable oil is one of the best alternatives for diesel needs. Pongamia pinnata is a evergreen tree had a high capacity to become an alternative fuel for replacing diesel fuel. Pongamia oil cannot be used directly, why because its having high viscosity compare to diesel fuel, and so affects the characteristics of combustion. The oil of pongamia is esterifies to decrease the value of viscosity and based on volume it was blended with diesel for different proportions. And the energy of the biodiesel may be released high efficiently by the concept of Low Heat Rejection (LHR) engine. In this experiment applying Thermal Barrier Coatings (TBC) onto engine parts of cylinder head, piston and valves for improving performance of engine; pongamia oil was used as an alternative fuel. So normal diesel engine was converted as a LHR engine by applying yittria stabilized zirconia (TBC) layer with a thickness of $0.50 \mathrm{~mm}$ on the engine parts. And that engine were tested for different load
\end{abstract}

Keywords: Direct Injection Engine, LHR Engine, POME, Operational Parameters, and Combustion Characteristics, Yittria Stabilized Zirconia Coating

\section{INTRODUCTION}

The product of petroleum like petrol, diesel, etc exhausting but use of fuel increasing as use of vehicles increased. So it is great challenge to science and technology to overcome this difficulty. Use Biodiesel from vegetable oil provided an effective alternative way for fight against the problem of petroleum product.

Produce of biodiesel is very easy by using vegetable oil. Availability of seeds from trees like neem, Castrol, honge coconut etc can be used to produce oil.

\section{SCOPE OF THE PROJECT}

- Determining the characteristics of combustion and operating parameters of diesel fuel and POME on DI normal diesel and LHR engine.

- Finding the characteristics of combustion and operating parameters of diesel and POME blends on DI normal diesel and LHR engine.

- Comparing the characteristics of combustion and operating parameters of POME blends, and diesel, at various loads.

- Finding best blend which approaches and can replace diesel fuel

\section{METHODOLOGY}

Vegetable oil is having more viscosity it's required to reduce, to get near value of diesel. By using Transesterification methods vegetable oils is converted as biodiesel. Transesterificationnis the reaction of a triglycerideewith an alcohol and using catalyst to produce fattyyaciddalkyllesters and glycerollas shown in fig. finally will get pure biodiesel.

\section{THERMAL BARRIER COATED PARTS}

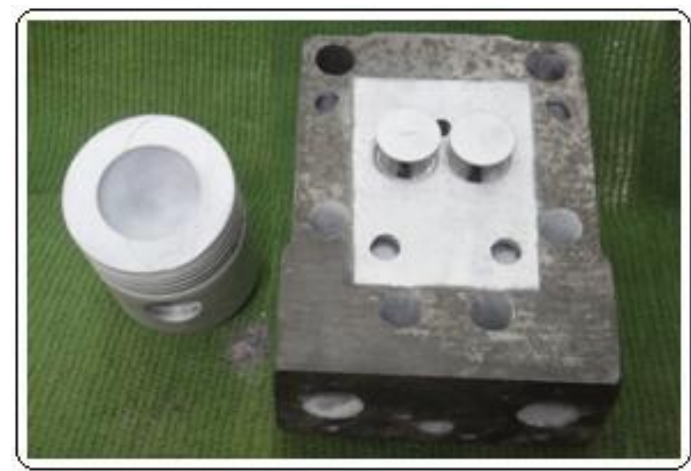

Fig 1: photograph of YSZ coated piston, Cylinder Head and Valves

\section{EXPERIMENTATION}

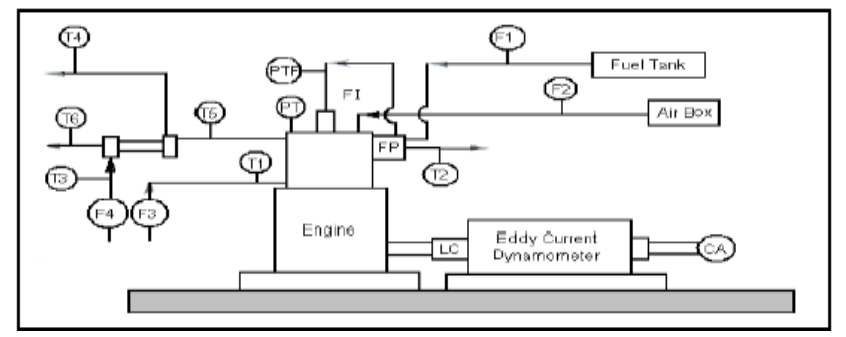

Fig.2: Experimental set up

\section{ENGINE SPECIFICATION AND COMPONENTS}

The following are the engine specifications for experimental setup shown in fig.3.6 
Engine parameters

Engine Type

Number of Cylinders

Number of Strokes

Rated power

@ 1500RPM

Bore

Stroke

Cubic Capacity

Compression Ratio

Rated Speed

\section{RESULT AND DISCUSSIONS}

Characteristics of combustion and operating parameters of diesel and pongamia biodiesel blends on Low Heat Rejection engine

\section{Air-Fuel ratio:}

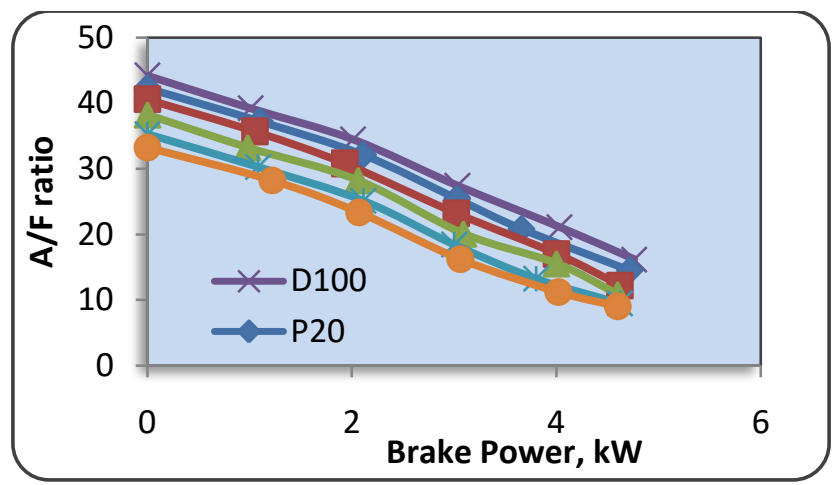

Fig 3: Air fuel ratio with different loads

Above fig Shows the variationnairrfuellratio and breakkpower for diesel and pongamia blendsson low heat rejection engine and it has been observed that air fuel ratio of P20 and D100 is almost near.P100 is requires more airfuel ratio than all fuels which is observed from graph.

\section{Brake Thermal Efficiency:}

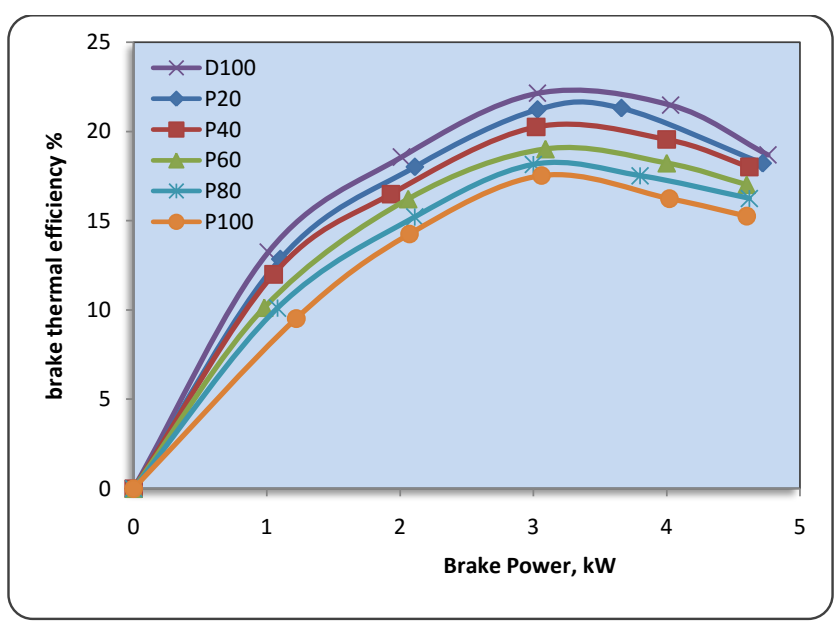

Fig 4: Brake thermal efficiency with different brake power

It observed that at fulllload break thermallefficiency is of $18.8 \%$ for diesel and $18.6 \%$ for P20 was obtained which is almost nearer, the main reason for increases in the brakeethermallefficiency of P20 is more homogeneous mixture formation and spray characteristic

\section{Specific Fuel Consumption}

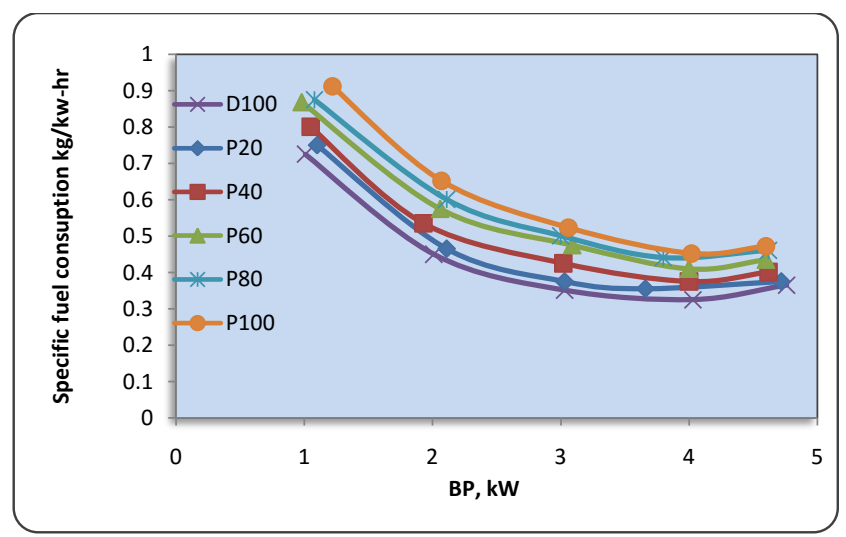

Figure:5 Specific fuel consumption with different load

Above sketch shows $20 \%$ blenddof pongamia biodiesel had the lowest SFC comparing to its other blends.

\section{Mechanical Efficiency:}

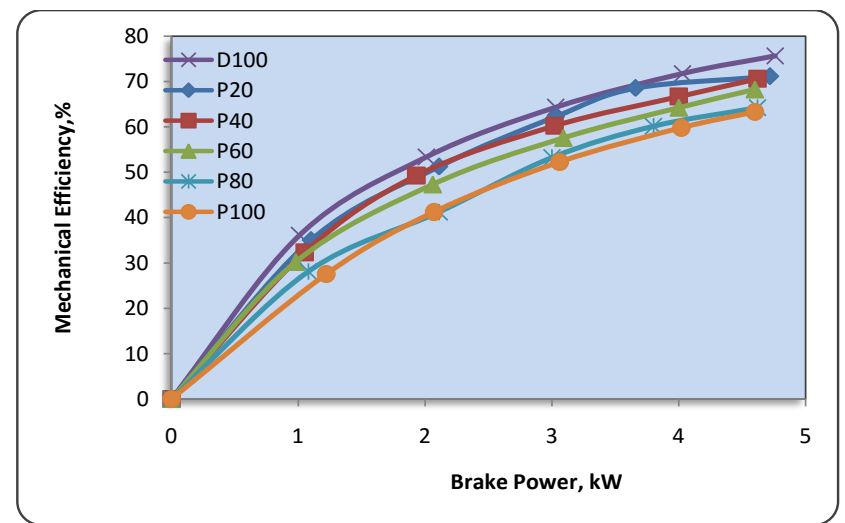

Fig 6: Mechanical efficiency with different loads

From above sketch $\mathrm{P} 20$ and D100 have almost same mechanical efficiency because of thermal barrier coating provides higher brake power and indicated power. We can also see that other pongamia biodiesel blends also have better mechanical efficiency due to thermal barrier coating.

\section{Indicated Mean Effective Pressure:}

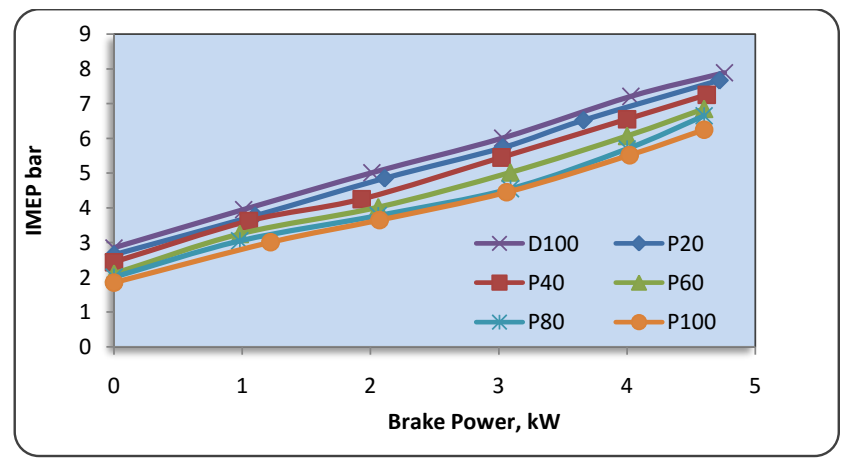

Fig 7: Variation of IMEP with different loads 
From above Sketch IMEP of P20 was 7.680 bars and for diesel 7.660 bar. Form fig it was evident that with increase in concentrations of POME blends increases the indicated mean effective pressure.

\section{Exhaust Emission Temperature:}

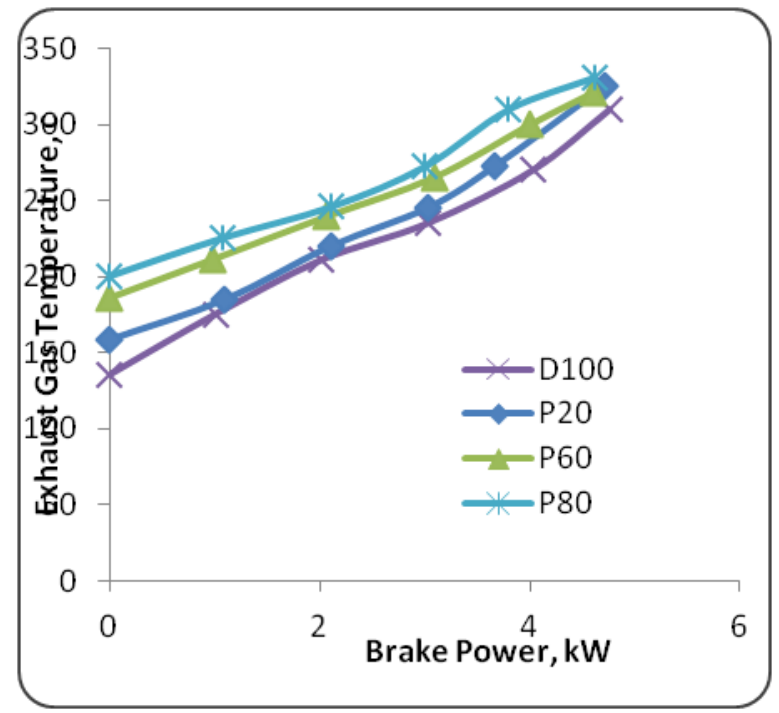

Fig 8: Exhaust gas temperature with Brake power

$20 \%$ blenddoffpongamia biodiesel has higherr performanceethen other blends due to reduced in Exhausttheattloss.

\section{Cylinder Pressure V/S Crank Angle:}

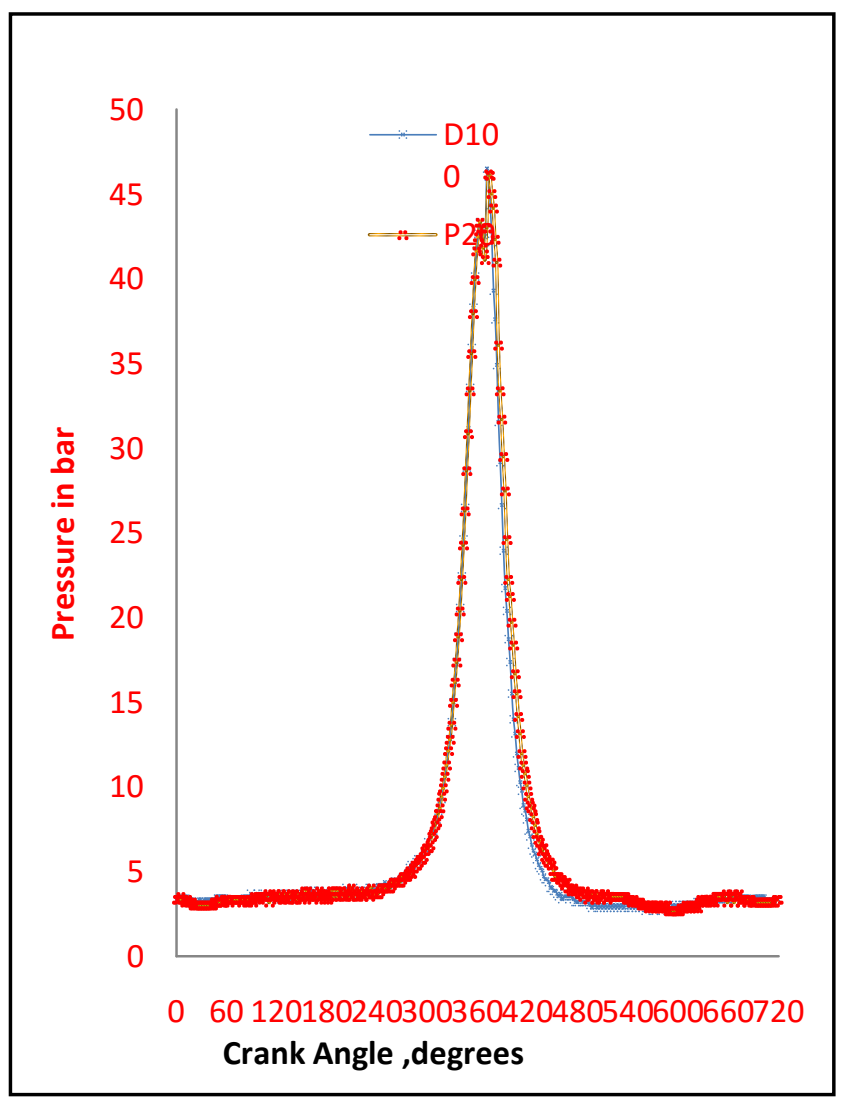

Fig 9: Cylinder pressure v/s crank angle
Above fig shows the cylinder pressureewithhrespect to crank angle. Peak pressures of 46.53bar and 46.31bar are found for pure diesel and P20 respectively.

\section{SUMMARY OF ABOVE RESULT DISCUSSION}

- Air fuel ratio of P20 and D100 is almost same and as the concentration of pongamia biodiesel increased the air fuel ratio also increased.

- Brake thermal efficiency for initial load of diesel, P20 and $\mathrm{P} 40$ are having almost same efficiency and at full load P20 and diesel are having almost same efficiency.

- Specific fuel consumption of P20 and P40 are lower than diesel at initial load and at full load it is almost same.

- Mechanical efficiency of P20 and diesel are almost having same efficiency and rest other blends are having nearer efficiency and similar nature of curves.

- More concentration of pongamia biodiesel in diesel increases the IMEP pressure which can observe from the graph.

- No major variations are found in case of peak pressure of diesel and $20 \%$ pongamia biodiesel blend because properties of biodiesel are brought almost closer to diesel by transisterification process but there is increase in peak pressure as compared to normal engine.

Hence from above discussion we can state that P20 and P40 have almost the same performance and combustion characteristics as that of diesel than rest all other blends. But we can see that with P100, also engine has better operational parameters and combustion characteristics than normal CI engine due to thermal barrier coating so we can say that pongamia oil methyl ester may be a good and more suitable alternative fuel for future years to come and with thermal barrier coating it can achieve needy requirements.

\section{CONCLUSION}

- The direct vegetable oils of pongamia pinnata have higher specific gravity and viscosity and low volatility as compared to diesel, therefore direct vegetable oil can not be used in CI engine.

- The pongamia pinnata is esterified to reduce the viscosity and it is blended with diesel on volume bases in different proportions.

Hence it may be stated that performancee and combustionncharacteristics on lowwheat rejectionnengineewith $\mathrm{P} 20 \%$ blend we can get same properties as that of diesel fuel, So P20 is the best blend it can be useddas alternate fuellfor diesell engine.

\section{REFFERENCES}

[1] Gholamhassan N.,2009. Combustion Analysis of a CI Engine Performance Using Waste Cooking Biodiesel Fuel with an Artificial Neural Network Aid. American Journal of Applied Sciences. 4: 7566-7644.

[2] EMa and Hanna. 2009. Biodiesel production: a review. Bioresource Technology. 70: 11-18. 
[3] Chopade VV Tankar AN, Pande VV Tekade AR,Phytochemical constituents, traditional uses and pharmacological properties: A review Int $\mathbf{J}$ Green Pharm.2009[cited 2009Apr28];2:78-6.

[4].M.S Kumar "An experimental comparison of methods to use methanol and Pongamia oil in a compression ignition engine",Biomass andBio Energy, Vol.25 2009, 3 